\title{
O PRINCÍPIO CONSTITUCIONAL DA IGUALDADE, A LEI MARIA DA PENHA E A MAGISTRATURA BRASILEIRA
}

\author{
Ivens Antônio Leite Júnior ${ }^{1}$
}

Resumo: O presente artigo utiliza do método indutivo, auxiliado pela técnica do referente, definindo categorias e apresentando conceitos operacionais, bem como fichamentos temáticos relativos à pesquisa bibliográfica realizada sobre o tema pesquisado. Para tanto, aborda inicialmente digressões acerca do controle de constitucionalidade, conceitos, contextualização histórica, classificação e métodos de controle. Define o princípio constitucional da igualdade, de forma a conceituá-lo. Expõe efetivamente a Lei 11.340/06, e ressaltada a importância do caso Maria da Penha Maia Fernandes na positivação da norma. Discute a constitucionalidade ou não do artigo 41 da Lei 11.340/06 destacando argumentação doutrinária e jurisprudencial pela constitucionalidade e inconstitucionalidade do dispositivo, trazendo ao leitor subterfúgios suficientes para firmar posicionamento, analisa decisões de alguns Tribunais brasileiros, expõe alguns entendimentos da magistratura brasileira acerca do assunto e a Ação Declaratória de Constitucionalidade que discute o tema deste artigo.

Palavras-chave: Constitucionalidade. Inconstitucionalidade. Princípio da Igualdade. Ação Declaratória de Constitucionalidade. Lei Maria da Penha.

1 Bacharel em Direito e Pós-Graduado em Segurança Pública pela Universidade do Contestado - UnC, Campus de Curitibanos-SC. Agente Penitenciário do Estado de Santa Catarina. Aluno da Escola Superior da Magistratura do Estado de Santa Catarina. E-mail: ivens@ssp.sc.gov.br 


\section{INTRODUÇÃO}

A Lei 11.340/06, mais conhecida como Lei Maria da Penha, surgiu no Direito pátrio com o intuito de coibir os casos de violência doméstica contra a mulher. Referido diploma legal, torna defeso o uso da Lei 9.099/95 nos casos tidos como de violência doméstica contra a mulher, por força do disposto no seu art. 41.

Pretende este artigo discutir o art. 41 da Lei 11.340/06 à luz do princípio constitucional da isonomia, a fim de identificar se aludida norma se encontra em consonância com a ordem constitucional vigente.

Objetiva precipuamente este trabalho discutir a existência de legitimidade para a vedação à utilização da Lei 9.099/95 na penalização dos praticantes de violência doméstica contra as mulheres; e visualizar como os magistrados e os tribunais brasileiros têm se posicionado nestes casos, vez que a lei dos Juizados Especiais é perfeitamente aplicável em casos especiais como os de crimes praticados contra crianças, adolescentes e idosos.

Assim, é preciso buscar uma justificativa jurídica consistente para explicar o tratamento mais severo dispensado à penalização da prática de crimes contra a mulher, no âmbito doméstico, em que pese o princípio constitucional da isonomia, verificando o imperativo de proporcionalidade no momento da reprimenda penal de crimes idênticos.

Para melhor desenvolvimento do tema se passara a discorrer inicialmente acerca do controle de constitucionalidade das leis de acordo com a legislação brasileira expondo apenas os tópicos que entende-se relevantes para a compreensão do tema. Visto que o presente artigo busca entre outros o exposição de jurisprudências, explicar-se-á apenas a forma de controle repressivo.

Em um segundo momento se expõe o princípio constitucional da igualdade mostrando ao leitor sua real extensão e profundidade; para na seqüência apresentar a Lei Maria da Penha e as mudanças que esta norma trouxe ao ordenamento 
jurídico pátrio. Estando o leitor contextualizado apresenta-se a problemática do artigo 41 da Lei 11.340/06 em relação a sua constitucionalidade. Aproveitando então para expor um estudo jurisprudencial sobre o assunto e subsidiariamente informar ao leitor da existência de uma Ação Declaratória de Constitucionalidade sobre o tema.

\section{CONTROLE DE CONSTITUCIONALIDADE DAS LEIS}

Antes de adentrar no tema principal deste estudo, que é a discussão da constitucionalidade da Lei Maria da Penha no que tange a aplicação do seu art. 41, é imperioso abordar o Controle de Constitucionalidade previsto no sistema jurídico pátrio. Tal análise tem o intuito de verificar a compatibilização da referida lei com o texto constitucional em vigência.

Controlar a constitucionalidade das normas e atos normativos infraconstitucionais é a garantia que tem o Estado para o respeito à supremacia da Constituição.

Sobre este tema, Alexandre de Moraes leciona que: "Controlar a constitucionalidade significa verificar a adequação (compatibilidade) de uma lei ou de um ato normativo com a constituição, verificando seus requisitos formais e materiais. (2007, p.691) (original sem grifo)

A CRFB prescreve esta fiscalização de constitucionalidade de duas formas, a preventiva e a repressiva. A primeira ocorre quando da produção normativa é exercida pelo Legislativo e pelo Executivo, que, ao apreciarem os projetos de leis devem evitar que se contraponham à Constituição. A segunda forma de fiscalização a repressiva, é praticada pelo Poder Judiciário de forma difusa ou concentrada e excepcionalmente pelo Legislativo. Tais formas serão, adiante, melhor analisadas. (BASTOS, 1998 p.47)

A Supremacia Constitucional é assegurada por consubstanciar a proteção dos direitos fundamentais e a forma de elaboração legislativa e seu conteúdo. Inconcebível, seria uma lei 
aprovada em processo legislativo ordinário tivesse valor superior à própria lei que regula tal processo.

A atual Constituição prevê que sua alteração só poderá ocorrer mediante um procedimento mais gravoso e formal do que o estipulado para as leis ordinárias, por isso diz-se que ela é uma Constituição rígida. (MORAES, 2007 p. 665)

A idéia de controle da constitucionalidade das normas, emanada desta rigidez, porque pressupõe a noção de um escalonamento normativo, ocupando a Constituição o grau máximo na aludida relação hierárquica, caracterizando-se como a norma de validade para os demais atos normativos do sistema. (LENZA, 2008, p.93)

O controle de constitucionalidade de uma norma pressupõe a análise de alguns requisitos formais e materiais, que facilitam a identificação da controvérsia. $O$ requisito formal exigido relaciona-se à eventual inobservância das normas constitucionais do processo legislativo. De outro norte, o requisito material diz respeito ao conteúdo específico das normas jurídicas, que, como destaca o doutrinador Alexandre de Moraes, é "a compatibilidade do objeto da lei ou do ato normativo com a Constituição Federal”. (MORAES, 2007 p. 579-580)

O controle formal é por excelência um controle jurídico, que se preocupa em identificar se a obra do legislador ordinário não transgride preceitos constitucionais pertinentes à organização técnica dos poderes ou às relações horizontais e verticais desses poderes, bem como, dos respectivos os ordenamentos estatais.

Nessa perspectiva, a inconstitucionalidade dita formal é o resultado da não observância das formas constitucionais pré-estabelecidas, e também obrigatórias, na oportunidade da elaboração da lei ou ato normativo.

O controle material de Constitucionalidade, por sua vez, analisa o conteúdo da norma, se reveste de um alto teor de politicidade para verificar o teor da matéria por ela regulada, busca acomodá-la aos cânones da Constituição, ao seu espírito, á sua 
filosofia, aos seus princípios políticos fundamentais. (BONAVIDES, 2001, p.269/270).

Por isso, diz-se que na inconstitucionalidade material, o vicio é oriundo do conteúdo discordante da norma ou do ato, em relação aos princípios estabelecidos constitucionalmente. (FERRARI, 2004, p. 75)

Desta forma, na análise da constitucionalidade das espécies normativas, é imprescindível observar o disposto no art. 59 da CF, a fim de verificar seus requisitos formais e matérias, para que se possibilite identificar existência ou não de sua compatibilidade com as normas constitucionais. (MORAES 2007, p.600)

O controle de constitucionalidade das normas pode ocorrer de diversas formas e em momentos diferentes. Tendo como ponto de partida o momento em que pode ser realizado o controle da constitucionalidade, podemos dividi-lo em preventivo e repressivo.

Via de regra, o controle da constitucionalidade de leis e atos normativos pela forma repressiva é exercido pelo Poder Judiciário, através de dois sistemas. Um, denominado concentrado ou reservado, via de ação. Outro, aberto ou difuso, via de exceção.

Controle difuso de constitucionalidade é o controle exercido pelo juiz singular ou tribunal em relação ao caso concreto. Sua principal característica é que só pode ser exercido no caso concreto e perante o Poder Judiciário.

Assim, posto um litígio em juízo, o Poder Judiciário deverá solucioná-lo e para tanto, incidentemente, deverá analisar a constitucionalidade ou não da lei ou do ato normativo. A declaração de inconstitucionalidade é necessária para o deslinde de um caso concreto, não sendo pois objeto principal da ação. (MORAES 2007, p.701)

No caso de órgãos colegiados julgando o controle de constitucionalidade no sistema difuso, a decisão somente terá validade se prolatada em sessão do pleno e por maioria absoluta, conforme determina artigo 97, da CRFB. 
Como o próprio nome supõe o controle concentrado de constitucionalidade é exercido de forma concisa por órgão único, o Supremo Tribunal Federal, a Corte Constitucional Brasileira, guardiã da atual Carta Magna.

O objetivo do sistema concentrado de controle de constitucionalidade é facilmente explicado por Alexandre de Moraes.

Por meio deste controle, procura-se obter a declaração de inconstitucionalidade da lei ou do ato normativo em tese, independentemente de existência de um caso concreto, visando-se a obtenção de invalidação da lei, a fim de garantir-se a segurança das relações jurídicas, que não podem ser baseadas em normas inconstitucionais. A declaração da inconstitucionalidade, portanto, é o objeto principal da ação, da mesma forma que ocorre nas Cortes Constitucionais européias, diferentemente do ocorrido no controle difuso, característica básica do judicial reviw do sistema norteamericano. (2007, p.720) (original sem grifo)

Existem cinco ações constitucionalmente previstas para fazer o controle concentrado de constitucionalidade: ação direta de inconstitucionalidade genérica, prevista do artigo 102, I, a; ação direta de inconstitucionalidade interventiva, prevista no artigo 36, III; ação direta de inconstitucionalidade por omissão, artigo $103, \S 2^{\circ}$; ação declaratória de constitucionalidade, artigo 102, I, a, in fine; e argüição de descumprimento de preceito fundamental, artigo $102 \S 1^{\circ}$.

Para desenvolvimento deste estudo, é importante que se explique a ação direta de inconstitucionalidade e declaratória de constitucionalidade, tendo em vista que nesta senda segue a abordagem da Lei Maria da Penha que se encontra em vigência.

A ADIn como também é conhecida diferentemente do controle difuso, tem como seu objeto unicamente a lei ou ato normativo de que se discute a inconstitucionalidade, assim sendo, o efeito de sua decisão será erga omnes, terá validade para todos os cidadãos que eram abrangidos pela norma discutida. 
O ADC foi incluída na CRFB através da Emenda Constitucional (EC) n 3, de 1993, que alterou o artigo 102 da Carta Magna, criando este mecanismo que é utilizado para tornar absoluta a constitucionalidade de lei ou ato normativo federal. O seu procedimento é regulado pela lei 9.868/99, mesma lei que regula o procedimento da ADIn. Na realidade, o tramite processual de ambas é o mesmo.

\section{O PRINCÍPIO CONSTITUCIONAL DA IGUALDADE}

O presente estudo tem como premissa discutir o artigo 41 da lei Maria da Penha à luz do princípio constitucional da igualdade, de forma que, ao término do trabalho, o leitor possa concluir pela sua constitucionalidade ou não. Por isso, este capítulo é dedicado à definição deste princípio basilar do Direito, e a exposição da Lei 11.340/06, mais conhecida como "Lei Maria da Penha”.

O tema "Igualdade" é um assunto já debatido e estudado em todas as esferas do conhecimento, justamente pelo fascínio que tal tema causa no pesquisador e no próprio leitor. Aparentemente tudo que se refere a ele já se encontra positivado em alguma tese, mesmo assim, por questões técnico-didáticas, é necessário localizar e definir o princípio da igualdade no Direito Brasileiro.

O princípio da Igualdade ou da isonomia, como também é conhecido, encontra-se consagrado no artigo $5^{\circ}$ da CRFB, logo no caput, onde dispõe que: "Todos são iguais perante a lei, sem distinções de qualquer natureza [...]”. 'A lei é feita para todos', independente de gênero, raça, cor ou credo, todos se submetem à mesma norma e por ela devem ser tratados de forma isonômica. (VADE MECUM, 2008, p. 31)

O primeiro inciso deste artigo preconiza que: "I - homens e mulheres são iguais em direitos e obrigações nos termos desta Constituição", se expressa ai a igualdade entre gêneros. Vê-se neste inciso a busca por uma igualdade mais justa que a do 
caput de artigo $5^{\circ}$, um tratamento isonômico que tenta igualar os desiguais. Busca tal artigo, o convívio de todos sem qualquer distinção, pressupõe oportunidades iguais para aptidões iguais, dentro de critérios e objetivos razoáveis. (VADE MECUM, 2008, p. 31)

A isonomia divide-se em dois itens bastante distintos: igualdade formal e o da igualdade material. A primeira é a igualdade na lei, o legislador deve tratar isonomicamente os indivíduos. A segunda trata-se da igualdade perante a lei, refere ao tratamento igualitário das partes de forma que durante a aplicação da norma as diferenças entre elas sejam suprimidas pelos critérios utilizados para este tratamento equânime.

José Afonso da Silva ao comentar o caput do artigo quinto da atual Carta Magna muito bem leciona.

As constituições só têm reconhecido a igualdade no sentido jurídico-formal: igualdade perante a lei. A Constituição de 1988 abre o capítulo dos direitos individuais com o princípio de que todos são iguais perante a lei, sem discriminação de qualquer natureza (art. $5^{\circ}$, caput). Reforça o princípio com muitas outras normas sobre igualdade ou buscando a igualização dos desiguais pela outorga de direitos sociais substanciais. Assim é que, já no art. 5º, I,declara que, homens e mulheres são iguais em direitos e obrigações. (2000, p.214) (original com grifo)

Formalmente, a igualdade nada mais é que o tratamento igualitário dos indivíduos abrangidos por determinada norma de direito. Este tipo de igualdade se aplicada de uma forma universal, ao invés de fazer justiça acabaria tendo o efeito contrário. Visto que o tratamento isonômico formal intraclasses iria apenas acentuar as diferenças existentes entre classes.

A igualdade material se refere ao tratamento isonômico das partes de forma que as diferenças entre elas sejam suprimidas pelos critérios utilizados para este tratamento igualitário.

Neste sentido é possível colocar como a igualdade perante a lei, levando em conta a sua aplicação prática pelos órgãos 
executores da norma, sendo dever destes aplicar a norma de forma a equiparar os indivíduos por ela abrangidos.

Conforme preconiza o jurista Marcelo Amaral da Silva, em seu artigo científico intitulado "Digressões acerca do princípio constitucional da igualdade", ao destacar que:

A igualdade material tem por finalidade a busca pela equiparação dos cidadãos sob todos os aspectos, inclusive o jurídico, como afirma Celso Ribeiro Bastos: 'Todos os homens, no que diz respeito ao gozo e fruição de direitos, assim como à sujeição a deveres'. (SILVA, 2003, p. 4-5 )

Deve o legislador buscar uma igualdade material, de forma que as leis tratem os iguais com igualdade e os desiguais desigualmente, objetivando sempre o equilíbrio e a justiça real.

Impossivel falar de igualdade material sem lembrar as poéticas palavras de Rui Barbosa, em seu discurso 'Oração aos Moços':

A regra da igualdade não consiste senão em aquinhoar desigualmente os desiguais, na medida em que se desigualam. Nesta desigualdade social, proporcionada à desigualdade natural, é que se acha a verdadeira lei da igualdade. Os mais são desvarios da inveja, do orgulho e da loucura. Tratar com desigualdade os iguais, ou desiguais com igualdade, seria desigualdade flagrante, e não igualdade real. Os Apetites Humanos conceberam inverter a norma universal da criação, pretendendo, não dar a cada um, na razão do que vale, mas atribuir o mesmo a todos, como se todos se equivalessem. (2004, p.33)

A hermenêutica moderna não pode deixar de considerar que as normas devem ser utilizadas com a finalidade de igualar os desiguais, privilegiando a igualdade material sobre a igualdade formal.

Quando se trata da questão de identificar o desrespeito da norma ou do fato que é posto em análise, frente ao princípio da 
isonomia, a doutrina é praticamente unânime ao citar o triplo questionamento apresentado por Celso Antonio Bandeira de Mello, que leciona:

Parece-nos que o reconhecimento das diferenciações que não podem ser feitas sem quebra da isonomia se divide em três questões:

a) a primeira diz com o elemento tomado como fator de desigualação;

b) a segunda reporta-se à correlação lógica abstrata existente entre o fator erigido em critério de discrimen e a disparidade estabelecida no tratamento jurídico diversificado;

c) a terceira atina a consonância desta correlação lógica com os interesses absorvidos no sistema constitucional e destarte juridicizados.(2006, p.21) (original com grifo)

Tais questionamentos podem ser mais bem esclarecidos da seguinte forma: em uma primeira etapa, é necessário determinar o que está sendo aplicado como critério discriminatório na lei ou fato; em uma segunda, deve-se verificar se existe uma justificativa racional, um fundamento lógico, para se aplicar, em função desta disparidade, tratamento jurídico específico feito exatamente para equilibrar as partes; e finalmente, resta analisar se este critério utilizado para impor tratamento desigual ás partes buscando sua equiparação, encontra-se em harmonia com os preceitos constitucionais ou com a jurisdição em geral.

Ainda de acordo com a dissertação de Celso Antonio Bandeira de Mello, para verificar se uma norma está em consonância com o princípio da isonomia, não basta analisá-la sob o prisma de um único questionamento supra elencados, mas sim de todo o conjunto. (MELLO, 2006, p.21) 


\section{A LEI MARIA DA PENHA}

O poder executivo, através de um Grupo de Trabalho Interministerial ${ }^{2}$, formulou o Projeto de Lei 4.559/2004, o qual deu origem ao Projeto de Lei de Conversão número 37/2006 que tramitou junto ao Senado Federal. Destes originou-se a Lei 11.340 sancionada pelo presidente da república em sete de agosto de dois mil e seis, tendo entrado em vigor em vinte e dois de setembro do mesmo ano.

A Lei tem como nascedouro, tratados internacionais sobre direitos humanos assinados pelo Brasil, mais especificadamente, a Convenção sobre a Eliminação de Todas as Formas de Discriminação contra a Mulher (Convention on the Elimination of All Forms of Discrimination against Women, CEDAW); e Convenção Interamericana para Prevenir, Punir e Erradicar a Violência Doméstica contra a Mulher, concluída em Belém do Pará (conhecida Convenção de Belém do Pará) (VADE MECUM, 2008, p.2021)

Peça fundamental para a elaboração da Lei 11.340/2006, o relatório número 54/2001 da Comissão Interamericana de Direitos Humanos, órgão específico da Organização dos Estados Americanos, condena internacionalmente o Brasil por omissão e negligencia para com os casos de violência doméstica no país.

A Lei foi sancionada em ato público, de forma solene, com a presença a senhora Maria da Penha Maia Fernandes, motivadora do relatório 54/2001 da Comissão Interamericana de Direitos Humanos; fato, sem o qual, possivelmente, a normatização de método para erradicar a violência doméstica contra a mulher não ocorresse ainda nesta década. (DIAS, 2007, p.14)

2 Grupo interministerial coordenado pela Secretaria Especial de Políticas para as Mulheres da Presidência da República, tinha como integrantes: Casa Civil da Presidência da República; Advocacia-Geral da União; Ministério da Saúde; Secretaria Especial dos Direitos Humanos da Presidência da República; Secretaria Especial de Políticas e Promoção de igualdade racial da Presidência da República; Ministério da Justiça; e Secretaria Nacional de segurança Pública. 
Por tal motivo a Lei fora "Apelidada" de Lei Maria da Penha, nomenclatura que irrefutavelmente se perpetuará no tempo.

O objetivo desta norma foi abordado em seu artigo primeiro ficando definido a partir de então a que vem a lei, e para quem se destina; vejamos o que prescreve tal artigo: "Art. 10 Esta Lei cria mecanismos para coibir e prevenir a violência doméstica e familiar contra a mulher,..." (VADE MECUM, 2008, p. 2021) (original sem grifo)

Rogério Sanches Cunha e Ronaldo Batista Pinto destacam que "a Lei 11.340/2006 extraiu do caldo da violência comum uma nova espécie, qual seja, aquela praticada contra a mulher (vítima própria), no seu ambiente doméstico, familiar ou de intimidade" (2007, p. 20). Conclui-se, portanto, que com a referida norma, o legislador objetivou proteger exclusivamente o gênero feminino, que sofre violência doméstica.

A norma também trouxe algumas inovações às práticas jurídicas; fazendo com que todas as entidades aplicadoras do direito tivessem de se adaptar ao novo ordenamento, com destaque às medidas preventivas, situações que podem ser visualizadas nos artigos da "Lei Maria da Penha", que não são objetos do presente estudo. Sendo sua proposta analisar a compatibilização do artigo 41 da Lei 11.340/06 com o princípio constitucional da igualdade, estabelecido no art. $5^{\circ}$, inciso I, da CRFB, propiciando alternativas para a possível identificação da constitucionalidade ou inconstitucionalidade do referido dispositivo.

\section{A (IN)CONSTITUCIONALIDADE DO ARTIGO 41 DA LEI 11.340/06}

Através do artigo 41 a Lei 11.340/2006 vedou a utilização da Lei 9.099/95 (Lei dos Juizados Especiais); nos crimes de violência doméstica contra mulher. "Art. 41. Aos crimes praticados com violência doméstica e familiar contra a mulher, independentemente da pena prevista, não se aplica a Lei 9.099. 
de 26 de setembro de 1995."(VADE MECUM, 2008, p. 2021) (original sem grifo)

A lei 9.099/95 refere-se aos Juizados Especiais Cíveis e Criminais e dá outras providências.No caso específico, os Juizados Especiais Criminais foram criados com o objetivo de oportunizar maior celeridade e economia processual às lides que envolvessem crimes de menor potencial ofensivo, o que se positivou da seguinte forma:

Art. 60. O Juizado Especial Criminal, provido por juízes togados ou togados e leigos, tem competência para a conciliação, o julgamento e a execução das infrações penais de menor potencial ofensivo, respeitadas as regras de conexão e continência. (Redação dada pela Lei $n^{\circ} 11.313$, de $\underline{2006)}$

(...)

Art. 61. Consideram-se infrações penais de menor potencial ofensivo, para os efeitos desta Lei, as contravenções penais e os crimes a que a lei comine pena máxima não superior a 2 (dois) anos, cumulada ou não com multa. (Redação dada pela Lei ${ }^{\circ}$ $\underline{11.313, \text { de 2006) }}$

Art. 62. O processo perante o Juizado Especial orientar-se-á pelos critérios da oralidade, informalidade, economia processual e celeridade, objetivando, sempre que possível, a reparação dos danos sofridos pela vítima e a aplicação de pena não privativa de liberdade. (VADE MECUM, 2008, p.1711)

Os Juizados Especiais Criminais têm previsão constitucional no artigo 98 inciso I, cujo texto legal permite a União no Distrito Federal e Territórios e aos Estados a criação de tais mecanismos que na esfera criminal teriam a competência de julgar crimes de menor potencial ofensivo.

Como se observa no texto legal o legislador utilizou como critério para identificar o que é crime de menor potencial ofensivo a pena máxima cominada aos crimes. Assim sendo os 
crimes cuja pena máxima for de até 2 anos a competência para processar e julgar é do Juizado Especial Criminal.

O artigo 41 da Lei 11.340/06, ao impedir a aplicação da Lei 9.099/95 nos casos de violência doméstica contra a mulher, independente da pena prevista aos crimes praticados sobre outras circunstâncias, acaba por desconsiderar a distinção de crimes de menor e maior potencial ofensivo. $O$ critério de aplicação da pena passa a ser a característica específica da vítima e não o tipo penal.

Deste modo, qualquer crime que seja praticado contra a mulher no âmbito doméstico, passa a ser tratado como crime de maior grau de potencialidade ofensiva.

Traçando um paralelo entre o artigo 41 da Lei 11.340/06 e o princípio da igualdade, percebe-se que pelo aspecto formal este artigo não respeita tal princípio justamente por tratar de forma distinta a mulher vítima de violência familiar e o homem vítima do mesmo crime.

No caso da mulher, o seu agressor não poderá desfrutar da transação penal, da suspensão condicional da pena, e demais medidas despenalizadoras, invocadas pela Lei dos Juizados Especiais, o que traria ao agressor material e processualmente, por exemplo a não prisão.

Por um ponto de vista material observa-se que a Lei Maria da Penha procura equiparar a Mulher, ser mais frágil, ao Homem que historicamente tem uma vida dominadora. Resta então saber se o fator utilizado pelo legislador ao proibir a utilização do Juizado Especial nos casos pertinentes à esta lei especial não excede a proporção da desigualdade existente entre os gêneros.

Para determinar isto é necessário estudar a norma de acordo com o triplo questionamento apresentado por Celso Antônio Bandeira de Mello discutido na segunda seção. (MELLO, 2006, p. 21)

Faz-se necessário eleger ainda, qual é o fator de discriminação desta relação jurídica. No caso tem-se como indivíduos 
abrangidos pela lei a mulher vítima de violência familiar e o agressor; o fator de discriminação seria a fragilidade, a dificuldade para se defender alem de vários outros fatores culturais de dependência e repressão que afetam a maiorias das mulheres em nossa sociedade.

Em uma segunda etapa é preciso definir se existe ligação entre o fator discriminatório que se observou e a diferenciação aplicada pela norma. O legislador no caso do artigo 41 da lei 11.340/06 utiliza como fator de busca de equilíbrio a proibição da utilização da Lei 9.099/95 nos crimes de violência familiar que tenha como vítima a mulher. Este fator atinge diretamente o agressor que praticar crimes com penas máximas cominadas igual ou inferiores a dois anos de detenção. (VADE MECUM, 2008, p. 20021)

Para tal resposta deve-se buscar inicialmente quais espécies de crimes se encaixam como de menor potencial ofensivo; podemos citar de pronto injúria, difamação e ameaça, as lesões corporais leves não se encaixam, pois esta mesma lei 11.340/06 aumentou a sua pena máxima para 3 anos quando praticada em caráter de violência doméstica. Em um segundo momento as conseqüências penalizadoras que a pratica de tais crimes em um ambiente doméstico e com a vítima mulher causariam, pela impossibilidade de aplicação da Lei 9.099/95. O procedimento Policial seria a abertura de um inquérito ao invés de um Termo Circunstanciado que tem implicações jurídicas bastante distintas; no caso de a polícia ter interferido durante a prática do delito ou logo após, caberá a prisão em flagrante do agressor; o agressor responderá a todo o processo penal e não poderá transacionar ou obter o benefício do sursis; e no fim do processo no caso de condenação, a pena aplicada não poderá ser alternativa, ou puramente pecuniária, será uma pena restritiva de direitos e de liberdade, mesmo que em regime aberto, todavia, restritiva de liberdade.

Após toda essa reflexão teve-se chegar a uma posição final no sentido de determinar se há ligação lógica entre o fator discri- 
minante, a fragilidade e inferioridade feminina, a discriminação utilizada, a proibição de que o agressor possa se beneficiar da Lei 9.099/95. Existindo uma ligação lógica e justa, passa-se para o terceiro e último passo, analisar se a discriminação utilizada para igualar a relação doméstica entre Homens e Mulheres além de ter uma ligação lógica com o fator discriminante, encontrase acobertada pelos preceitos pelos quais vige a Constituição Federal do Brasil.

A igualdade de gêneros fora agraciada com destaque na Carta Magna, estando elencada no inciso primeiro do artigo 5 que acolhe os direitos fundamentais do cidadão. "I - homens e mulheres são iguais em direitos e obrigações nos termos desta Constituição", em uma primeira análise vemo-se que o fator gênero encontra-se na Constituição como se vislumbra na primeira parte do inciso, "Homens e Mulheres são igual perante a lei”, o que poderia justificar a discriminação existente no artigo.

Porém a discussão de constitucionalidade ou não desta discriminação em debate tem como tema a parte final do inciso, "Homens e Mulheres são iguais perante a lei, nos termos desta constituição", entra-se agora em uma discussão de hermenêutica. Qual a intenção do legislador constituinte em registrar que a igualdade entre gêneros seria regulada pela Constituição? Está-se diante de uma sentença que restringe a diferenciação entre homens e mulheres à matéria positivada na Constituição ou aos preceitos que ele defende?

As conclusões obtidas com a análise deste triplo questionamento formulado por Celso Antonio Bandeira de Mello faz com que se determine a constitucionalidade ou não do artigo em discussão frente ao princípio constitucional da igualdade, sendo que neste sentido ainda se apresentam argumentos próconstitucionais e aspectos inconstitucionais. 


\section{A MAGISTRATURA BRASILEIRA E O ARTIGO 41 DA LEI 11.340/06}

A Magistratura brasileira têm apresentado decisões das mais diversas formas frente ao tema abordado. Buscaram-se junto aos tribunais e a bibliografia decisões que demonstrassem como têm se posicionados os Magistrados brasileiros ao decidir casos concretos que envolvem o artigo 41 da Lei Maria da Penha.

Um dos temas que alimentam discussões é sobre o tipo da ação penal pela qual serão dirimidas as lides envolvendo crimes que anteriormente eram tidos como de menor potencial ofensivo e por virtude do artigo deixaram de ser; será esta ação publica condicionada a representação da vítima ou publica incondicionada?

O Tribunal de Justiça do Estado de Goiás, através de sua Segunda Câmara Criminal têm se posicionado da seguinte forma:

HABEAS CORPUS. VIOLENCIA DOMESTICA. LEI 11.340/06. CRIME DE ACAO PENAL PUBLICA INCONDICIONADA. INEPCIA DA DENUNCIA. INOCORRENCIA. A LESAO CORPORAL CULPOSA E DOLOSA SIMPLES CONTRA MULHER EM AMBIENCIA DOMESTICA, FAMILIAR OU INTIMA, PASSOU A SER, DESDE A EDICAO DA LEI MARIA DA PENHA, DE ACAO PENAL PUBLICA INCON. DICIONADA, PRESCINDINDO, PORTANTO, DE DIREITO DE REPRESENTACAO DA VITIMA. NAO HA FALAR-SE EM INEPCIA DA DENUNCIA QUANDO ESTA QUALIFICA O DENUNCIADO, DESCREVE SATISFATO. RIAMENTE FATO QUE, EM TESE, E TIPICO E OFERECE INDICIOS DE AUTORIA ATRIBUIDA A ELE, PERMITINDO-SE-LHE O EXERCICIO DA AMPLA DEFESA. ORDEM DENEGADA. (GOIAS, 2008, p1)

Como se vislumbra a ementa do acórdão proferido junto aos autos de Habeas Corpus n. 2008.0059163-6, relata que o 
entendimento daqueles nobres Desembargadores é o de que a Ação penha oriunda de crime praticado contra mulher no âmbito doméstico deve ser publica incondicionada, ou seja, independe da vontade a vítima.

De forma diversa os membros da Segunda Câmara de Direito Criminal do Egrégio Tribunal do Estado de Santa Catarina têm se posicionado em caso bastante similar, vejamos:

RECURSO EM SENTIDO ESTRITO - LEI N. 11.340/2006 - LESÕES CORPORAIS LEVES COMETIDAS CONTRA MULHER NO ÂMBITO DOMÉSTICO E FAMILIAR - AÇÃO PENAL DE INICIATIVA PÚBLICA CONDICIONADA À REPRESENTAÇÃO DA OFENDIDA - INTERPRETAÇÃO DOS ARTS. 16 E 41 DA LEI MARIA DA PENHA - DECISÃO QUE JULGOU EXTINTA A PUNIBILIDADE DO RÉU - RETRATAÇÃO DA VÍTIMA ANTERIOR AO RECEBIMENTO DA DENÚNCIA ACOLHIMENTO DA VONTADE DA PARTE - FALTA DE CONDIÇÃO DE PROCEDIBILIDADE (CPP, 43, III) - DECISÃO MANTIDA.

I - Entende-se que ao afastar a aplicabilidade da Lei dos Juizados Especiais em seu art. 41 e, também, possibilitar a retratação da vítima em seu art. 16, a Lei n. 11.340/2006 não pretende transformar a ação penal, que é condicionada para os casos de lesão corporal leve e culposa, em incondicionada, porquanto visou apenas a coibir a utilização dos institutos da suspensão do processo e da transação penal, por considerálos respostas penais insuficientes à repressão que deve ser imposta pela ofensa ao bem jurídico tutelado.(...) (original sem grifo)(SANTA CATARINA, 2011, p1)

Como se percebe os Desembargadores Catarinenses, não estão em consonância com seus colegas Goianos, visto que interpretam o mesmo artigo de forma totalmente antagônica. 
Têm porem os magistrados Catarinenses decidido da mesma forma que os Ministros no Superior Tribunal de Justiça, que em sua Quinta Turma julgou o Habeas Corpus n. 2009/0222520-6 conforme ementa:

PROCESSUAL PENAL. HABEAS CORPUS. LESÃO CORPORAL LEVE. LEI MARIA DA PENHA. AÇÃO PENAL PÚBLICA CONDICIONADA À REPRESENTAÇÃO DA OFENDIDA. APLICAÇÃO DA LEI No 9.099/95. RESTRIÇÃO. INSTITUTOS DESPENALIZADORES.

I - A intenção do legislador ao afastar a aplicação da Lei n. ${ }^{9}$ 9.099/95, por intermédio do art. 41 da Lei Maria Penha, restringiu-se, tão somente, à aplicação de seus institutos específicos despenalizadores - acordo civil, transação penal e suspensão condicional do processo.

II - A ação penal, no crime de lesão corporal leve, ainda que praticado contra a mulher, no âmbito doméstico e familiar, continua sujeita à representação da ofendida, que poderá se retratar nos termos e condições estabelecidos no art. 16 da Lei n. ${ }^{\circ}$ 11.340/06 (Precedentes).(...)(original sem grifo) (BRASIL, 2011, p1)

Pacificamente tem se posicionado o Superior Tribunal de Justiça nas ação similares e é bastante provável que este entendimento torne-se consolidado.

Outro caso que se mostrou interessante é a discussão sobre a possibilidade ou não de se utilizar do instituto da Lei Maria da Penha nos processos que envolvam contravenções penais. Apesar do artigo 41 na lei nada mencionar em relação as contravenções a Oitava Câmara Criminal do Tribunal de Justiça do Estado do Rio Grande do Sul têm decidido da seguinte forma:

Ementa: CONFLITO NEGATIVO DE JURISDIÇÃO. CONTRAVENÇÃO PENAL. APLICAC̣ÃO DA LEI No 11.340/2006. COMPE- 
TÊNCIA DO JUÍZO COMUM. Se a hipótese retrata situação de violência doméstica contra a mulher, a exigir a incidência dos dispositivos protetivos da denominada 'Lei Maria da Penha, independente de configurar crime ou contravenção penal, a competência para o processamento e julgamento do feito recai no juízo criminal comum, considerando-se, inclusive, a vedação contida no art. 41 da Lei n. 11.340/06 que pretende, em suma, tratar com maior rigor o acusado da prática de delitos dessa natureza. CONFLITO DE COMPETÊNCIA PROCEDENTE. (original sem grifo) (RIO GRANDE DO SUL, 2011, p1)

A Oitava Câmara Gaúcha tem decidido em algumas argüições de conflito de competência entre Juizados Especiais Criminais e o Juízo Criminal Comum, que pela especificidade da lei mesmo em caso de contravenções a competência para julgamento é da justiça comum, procedimento ordinário. Ao passo que a Quinta Câmara Criminal do mesmo Tribunal, o do Rio Grande do Sul prolata decisões em sentido totalmente contrário, como demonstra a decisão colacionada:

Ementa: Conflito negativo de competência. Contravenção penal. Perturbação da tranqüilidade (art. 65, LCP). Lei n. ${ }^{\circ}$ 11.340/06 (Lei Maria da Penha). Inaplicabilidade da Lei n. ${ }^{\circ}$ 9.099/95 prevista no art. 41 do novo diploma legal alcança só os crimes, não atingindo as contravenções penais, que seguem na competência do Juizado Especial Criminal. Conflito procedente. Unânime. (original sem grifo)(RIO GRANDE DO SUL, 2011, p1)

As decisões proferidas acerca da matéria são varias, com os mais diferentes posicionamentos, motivados por argumentação diferenciada na mesma proporção. Como demonstrado, é possível encontrar posicionamento divergente e Câmaras Criminais de um mesmo tribunal. Pelo que constatou durante a pesquisa, tais fatos continuarão constantes até que o Supremo Tribunal de Justiça profira decisão sobre o tema. 


\subsection{Análise da ADC/19}

O artigo 41 da lei 11.340, esta sendo discutida também pelo Controle Concentrado de Constitucionalidade, através de uma Ação Declaratória de Constitucionalidade. Como visto no primeiro capítulo, nesta forma de controle, não se discute caso concreto, mas especificadamente o dispositivo jurídico e seu respeito aos preceitos defendidos pela Carta da República.

O tramite da ADC e da Ação Direta de Inconstitucionalidade são praticamente os mesmos, e a sua finalidade também, como já relatado, a lei 9.868/99 trouxe um caráter de ambivalência à decisão destas ações, de forma que tanto decisão de uma quanto a da outra declararão a constitucionalidade ou a inconstitucionalidade do dispositivo discutido.

No dia 19 de dezembro de 2007, fora protocolado junto a Coordenadoria de processamento inicial do Supremo Tribunal Federal, uma Ação Declaratória de Constitucionalidade, proposta e subscrita pelo então Presidente da República, Sr. Luiz Inácio Lula da Silva, através do Advogado Geral da União. Recebendo a numeração de $\mathrm{ADC} / 19$, ela ainda se encontra em tramite.

Os autos encontram-se aguardando decisão, tendo, contudo, sido protocolados vários petitórios solicitando ingresso no feito na qualidade de amicus curiae. Até o momento foram admitidos como terceiros o Conselho Federal da Ordem dos Advogados do Brasil, Themis - Assessoria Jurídica e Estudos de Gênero, Ipê - Instituto para a Promoção da Equidade, o Instituto Antígona e o Instituto Brasileiro de Direito de Família - IBDFAM. (Brasil, 2007, p1)

Até a presente data este era o estado fático da ADC/19, resta aguardar a decisão de nossa Corte Suprema, que de forma definitiva encerrará com as discussões envolvendo a constitucionalidade ou não do artigo 41 da Lei 11.340/06.

Assim resta aguardar a decisão da Suprema Corte em relação à $\mathrm{ADC} / 19$, esperando que os ministros tomem a decisão acertada em respeito aos preceitos defendidos pela Constituição Cidadã. 


\section{CONCLUSÃO}

Passados cinco anos da promulgação e entrada em vigor da Lei Maria da Penha no ordenamento jurídico brasileiro, esta norma já se arraigou, e apesar das polemicas que ainda gera, os servidores do Direito têm a trabalhado com bastante tranqüilidade no dia-a-dia.

A discussão de princípios faz com que sejam pesados argumentos de todas as naturezas, traçando valores e medidas que a cada caso podem ser diferenciados.

O controle de constitucionalidade deixa um legado de que somente com a manutenção dos preceitos que regem a República estará garantida a segurança jurídica para a vida em uma sociedade soberana e democrática. A Constituição da República Federativa do Brasil não é apenas um livro de letras mortas; é a guardiã dos anseios de um povo que somente alcança seus objetivos depois de muito trabalho. A soberania da Constituição garante um ordenamento jurídico justo, sem privilégios e privilegiados.

A complexidade do princípio constitucional da isonomia é pedra fundamental na construção do Direito. As linhas que dividem o justo do injusto são mais finas que o fio da mais afiada navalha. Um erro por mais ínfimo que seja, sobre o fio desta navalha, pode dilacerar o direito de uma coletividade.

As mulheres brasileiras sempre buscaram um tratamento isonômico em relação aos homens e oportunidades que lhes são concedidas. Infelizmente a violência doméstica é mais uma das duras realidades do cotidiano de nosso país. Os lares contaminados com este mau, têm despejado indivíduos perturbados na sociedade. A pessoa que não tem segurança e conforto ao menos em seu lar não é uma pessoa saudável.

Era procurada uma medida de respeito ou não do artigo 41 da lei 11.340/08 ao princípio constitucional da igualdade e acabaram sendo encontradas respostas para todos os gostos. Os argumentos pela constitucionalidade ou inconstitucionalidade são bastante fortes e podem ensejar estudos mais aprofundados para ambos os lados. 
Pressupôs-se que o dispositivo estudado poderia não estar em consonância com o princípio constitucional da igualdade, encontraram-se argumentos tanto para confirmá-lo quanto para negá-lo.

Tendenciosamente conclui-se que o artigo 41 da Lei 11.340/06 é inconstitucional por ferir o princípio da isonomia. Assim conclui-se com base no artigo $5^{\circ}$ inciso primeiro da CRFB o qual prescreve a igualdade de direitos e deveres entre homens e mulheres, todavia, condiciona esta igualdade aos termos do texto constitucional. Se pretendesse que as discriminações possíveis entre gênero fossem outras diferentes das previstas na norma fundamental, o legislador a teria restringido.

Tem-se como injusto que esta lei especial proíba as medidas despenalizadoras de crimes de menor potencial ofensivo, nos crimes praticados em ambiente doméstico com vítima mulher, e o mesmo não ocorre nos crimes praticados contra vítima infante ou senil homem nas mesmas circunstâncias.

O posicionamento da Magistratura brasileira é o mais diverso e o menos pacificado possível. Os Tribunais de regiões diferentes têm divergido da mesma forma que não decidem uniformemente Tribunais da mesma região, nem sequer Câmaras Criminais de um mesmo Tribunal. Enquanto a Corte Constitucional não se posicionar acerca da matéria, decidindo a A.D.C. n. 19 continuar-se-á encontrar decisões a todos os nortes.

De toda sorte encerra-se este artigo cientifico com satisfação pelo resultado final que se obteve.

Abstract: The present article uses the inductive method together with the referent technique, defining categories and presenting operational concepts, and also thematic filing relative to literature research performed over the subject. Initially, it is approached the digressions about the control of the constitutionality, concepts, historic context, classification and control methods. Following, it is 
defined the constitutional principle of equality in order to conceptualize it. It is shown effectively the law 11340/06 and is highlighted the importance of the case Maria da Penha Fernandes in the positivation of the norm. It is discussed the constitutionality or not of article 41 of the law 11340/06 highlighting the doctrinal and jurisprudential argumentation from the constitutionality and inconstitutionality of the mechanism, bringing the reader enough subterfuges to hold positioning. Finally, it is analysed decisions of brasilian courts, showing some understandings of brazilian magistrature about the subject and about the Declaratory Action of Constitutionality which discuss over this article's subject.

Keywords: Constitutionality. Unconstitutionalit. Equality principle. Declaratory Action of Constitutionality. Law Maria da Penha.

\section{REFERÊNCIAS}

ALVIM, J. E. Carreira, Luciana Gontijo Carreira Alvim Cabral. Comentários às leis do Juizados Especiais Federais Civeis. 2. ed. Curitiba: Juruá, 2006.

ARAÚJO, Luiz Alberto David. Curso de Direito Constitucional. 10 ed. São Paulo . Saraiva, 2006.

ATUAÇÃO: Revista jurídica do Ministério Público Catarinense. ProcuraduriaGeral de Justiça e Associação Catarinense do Ministério Público.

Florianópolis: PGJ, v.5,n.11,jan./abr. 2007.

BASTOS, Celso Ribeiro. Curso de direito constitucional. 19. ed. atual. São Paulo: Saraiva, 1998.

BARBOSA, Rui de Oliveira. Oração aos Moços/ O dever do Advogado. 1. ed. Campinas: Russell, 2004.

BONAVIDES, Paulo. Curso de direito constitucional. 11. ed. rev., atual. e ampl. São Paulo: Malheiros, 2001.

BRASIL. Supremo Tribunal de Federal. Ação Declaratória de Constitucionalidade n. 19(em tramite). Brasília, DF, 19 de dez. 2007. Disponivel em: $<$ http://www.stf.gov.br/portal/processo/ 
verProcessoAndamento.asp?numero $=19 \&$ classe $=$ ADC\&origem $=$ AP\&rec $\underline{\text { urso }=0 \& \text { tipoJulgamento }=\mathrm{M}>}$.

.Superior Tribunal de Justiça. Habeas Corpus n. 156924/MS. Brasília, DF, 21 de set. 2010. Disponível em:< http://www.stj.jus.br/webstj/ Processo/justica/detalhe.asp?numreg $=200902427508$

CANOTILHO, J. J Gomes. Direito constitucional e teoria da constituição. Coimbra: Almedina. 1995.

CASTRO, Carlos Roberto Siqueira. O devido processo legal e os princípios da razoabilidade e da proporcionalidade. 4. ed. Rio de Janeiro: Forense, 2006.

CHIMENTI, Ricardo Cunha [et. al]. Curso de direito constitucional. 3 ed. São Paulo. Saraiva, 2006.

CUNHA, Rogério Sanches, e Ronaldo Batista Pinto. Violência doméstica Lei Maria da Penha (Lei 11.340/2006). 1 ed. São Paulo: Revista dos Tribunais, 2007.

DIAS, Maria Berenice. Lei Maria da Penha na Justiça: a efetividade da Lei 11.340/2006 de combate à violência doméstica e familiar contra a mulher. 1 ed. São Paulo: Revista dos Tribunais, 2007.

FERRARI, Regina Maria Macedo Nery. Efeitos da declaração de inconstitucionalidade. 5. ed. São Paulo. Revista dos Tribunais, 2004.

GOIAIS. HABEAS CORPUS No 200800591636, Segunda Câmara Criminal, Tribunal de Justiça de GO, Relator: DES. Aluizio Ataides de Sousa. Goiania, GO, 28 de fev. 2008. Disponível em: http://www.tjgo.jus.br/jurisprudencia/showacord.php?nmfil e=TJ_312525217_20080228_20080402_104741.PDF

LENZA, Pedro. Direito constitucional esquematizado. 12. ed., rev., atual. E ampl.. São Paulo: Saraiva, 2008.

LIMA FILHO, Altamiro de Araujo. Lei Maria da Penha comentários à lei de violência doméstica e familiar contra a mulher. 1 ed. 2 tir. Leme/SP: Mundo Jurídico, 2008.

MELLO, Celso Antônio Bandeira de. Conteúdo jurídico do princípio da igualdade. 3. ed., 14. tir. Malheiros: São Paulo, 2006.

MORAES, Alexandre de. Direito Constitucional. 22. ed. São Paulo: Atlas, 2007. 
. Direitos Humanos Fundamentais: teoria geral, comentários aos arts. $1^{\circ}$ a $5^{\circ}$ da Constituição de República Federativa do Brasil, doutrina e jurisprudência. 3. ed. São Paulo: Atlas, 2000.

RIO GRANDE DO SUL. Conflito de Jurisdição No 70040437246, Oitava Câmara Criminal, Tribunal de Justiça do RS, Relator: Danúbio Edon Franco, Porto Alegre, RS, 16 de mar. 2011. Disponível em: http://www1. tjrs.jus.br/site php/consulta/consulta processo.php?nome comarca= Tribunal+de+Justi $\%$ E7a\&versao $=\& v e r s a o$ fonetica $=1 \&$ tipo $=1 \& \mathrm{id}$ comarca $=700 \&$ num processo mask $=70040437246 \&$ num processo $=700$ $\underline{40437246 \& \text { codEmenta }=4048324 \& \text { temIntTeor }=\text { true }}$ . Conflito de Jurisdição No 70038954822, Quinta Câmara Criminal, Tribunal de Justiça do RS, Relator: Luís Gonzaga da Silva Moura. Porto Alegre, RS, 26 de mar. 2011. Disponível em: http://www1. tjrs.jus.br/site php/consulta/consulta processo.php?nome comarca= Tribunal + de + Justi $\%$ E7a\&versao $=\& v e r s a o$ fonetica $=1 \&$ tipo $=1 \& i d$ comarca $=700 \&$ num processo mask $=70038954822 \&$ num processo $=700$ $\underline{38954822 \& \text { codEmenta }=4023368 \& \text { temInt Teor }=\text { true }}$

SANTA CATARINA. Recurso Criminal No 2010.051504-5, Segunda Câmara Criminal, Tribunal de Justiça de SC, Relatora: Salete Silva Sommariva. Florianópolis, SC, 25 de mar. 2011. Disponível em: http://tjsc6.tj.sc.gov.br/cposg/pcpoResultadoConsProcesso2Grau. jsp?CDP=01000GVMT0000

SILVA, Jose Afonso da. Curso de direito constitucional positivo. 17. ed. São Paulo: Malheiros, 2000.

SILVA, Marcelo Amaral da. Digressões acerca do princípio constitucional da igualdade. Jus Navigandi, Teresina, ano 8, n. 66, 1 jun. 2003.

Disponível em: $\leq$ http://jus.uol.com.br/revista/texto/4143 $>$. Acesso em: 11 abr. 2011 .

SOUZA, Sérgio Ricardo. Comentários à lei de combate à violência contra a mulher. 2 ed. Curitiba: Juruá, 2008.

VADE MECUN RT. 3.ed. São Paulo: Revista dos Tribunais,2008. 